real assessment of hyaline cartilage structural changes and synovial inflammation.

\section{SAT0187 USE OF BONE SCINTIGRAPHY FOR INFLAMMATORY POLYARTHRITIS IN A TEACHING HOSPITAL RHEUMATOLOGY DEPARTMENT}

${ }^{1} \mathrm{~S}$ Siebert, ${ }^{2} \mathrm{~J}$ Rees, 'SM Jones. 'Rheumatology Department; ${ }^{2}$ Radiology Department, University Hospital of Wales, Cardiff, UK

10.1136/annrheumdis-2001.685

Background Bone scintigraphy using ${ }^{99 \mathrm{~m}}$ Technetium methylene diphosphonate $\left({ }^{99 \mathrm{~m}} \mathrm{Tc}\right.$ MDP) has been shown to be sensitive in detecting subclinical synovitis ${ }^{1}$ but lacks specificity for the aetiology of the articular disease. ${ }^{99 \mathrm{~m}} \mathrm{Tc}$ MDP scans may therefore have a role to play in identifyinginflammatory polyarthritis (IP) in selected patients, although it isrecognised that they cannot accurately differentiate between differentdegrees of activity in rheumatoid arthritis. ${ }^{2}$

Objectives To assess the value of ${ }^{99 \mathrm{~m}} \mathrm{Tc}$ MDP scans in inflammatory polyarthritis.

Methods All requests for bone scans for IP by the rheumatology department at the University Hospital of Wales over a $2 \frac{1}{2}$ year period were retrospectively assessed. The indications for the bone scan and the results were recorded. Degenerative changes on bone scan, confirmed on plain xrays, were considered negative for IP.

Results 94 bone scans were performed in total, of which 68 scans were done looking for possible IP. Of these, 17 (25\%) confirmed a pattern of uptake consistent with IP, $6(9 \%)$ were equivocal (possible IP) and $45(66 \%)$ revealed no evidence of IP. 1 patient with a negative ${ }^{99 \mathrm{~m}}$ Tc MDP scan subsequently developed psoriatic arthritis with erosions on plain films. In the subgroup of 45 patients with high ESR values, 9 (20\%) bone scans suggested an IP, 6 (13\%) were equivocal and 30 (67\%) were negative. ${ }^{99 \mathrm{~m}} \mathrm{Tc}$ MDP scans were requested regarding activity of arthritis in 7 patients with known rheumatoid arthritis, of which none were helpful in terms of altering management. 7 patients with seronegative arthritis underwent bone scintigraphy looking for evidence of peripheral joint involvement, which was demonstrated in $3(43 \%)$ patients.

Conclusion These results suggest that ${ }^{99} \mathrm{~m}$ Tc MDP bone scans may be helpful in patients with normal clinical examination if there is a pattern of uptake suggestive of IP. Negative bone scans can also be helpful in patients with polyarthralgia and elevated inflammatory parameters on blood tests, although it should be stressed that the diagnosis of rheumatoid arthritis remains a clinical one. It is not possible to comment on the degree of activity of arthritis on ${ }^{99 \mathrm{~m}} \mathrm{Tc}$ MDP scans, and these should therefore not be requested for this.

\section{REFERENCES}

1 Shearman J, Esdaile J, Hawkins D, Rosenthal L. Arthritis Rheum. 1982;25:83-6

2 De Bois MHW, Arndt JW, Van der Velde EA, Pauwels EKJ, Breedeveld FC. Br J Rheumatol. 1994;33:67-73
SAT0188 CHRONIC PLANTAR FASCIITIS: EVALUATION BY ULTRASOUND AND MRI. TREATMENT WITH ULTRASOUND GUIDED INJECTION

${ }^{1} \mathrm{R}$ Ghozlan, ${ }^{1} \mathrm{M}$ Dupuis, ${ }^{1} \mathrm{C}$ Lecarpentier, ${ }^{2} \mathrm{M}$ Delain. ${ }^{1}$ Rheumatology Service; ${ }^{2}$ Radiology Service, Hopital Europeen de Paris La Roseraie, Aubervilliers, France

\subsection{6/annrheumdis-2001.686}

Background Chronic plantar fasciitis is not very known and the diagnosis is frequently missed.

Trends for the diagnosis have been performed with the new methods of imaging.

Objectives Determine the abnormal features of the chronic plantar fasciitis and find an efficient and accurate method of treatment.

Methods 12 patients with chronic plantar fasciitis have been referred to us: men 7 , women 5 ; mean age 55 years; mean duration of the disease 10 months.

Ultrasound has been performed in 5 cases and MRI in 7 cases.

Results Imaging showed increased thickness, reduced echogenicity of the plantar fasciitis and/or inflammatory changes.

Ultrasound guided injection of steroids of the enlarged, hypoechoic plantar fascia, has been performed in 7 patients who had failed to conservative treatment.

Conclusion The procedure resulted in complete relief of symptoms in 6 of 7 patients.

\section{SAT0189 CLINICAL UTILITY OF DIAGNOSTIC TESTS FOR RHEUMATOID FACTOR}

${ }^{1} \mathrm{TM}$ Madland, ${ }^{2} \mathrm{E}$ Ulvestad, ${ }^{2} \mathrm{~A}$ Kaneström, ${ }^{1} \mathrm{E}$ Thomassen, ${ }^{1} \mathrm{HJ}$ Haga. ${ }^{1}$ Department of Rheumatology; ${ }^{2}$ Department of Microbiology and Immunology, Haukeland University Hospital, Bergen, Norway

10.1136/annrheumdis-2001.687

\section{Background}

Objectives To investigate and compare the accuracy and usefulness of diagnostic tests for rheumatoid factor (RF).

Methods In a cross-sectional study sera derived from patients admitted to the Department of Rheumatology were tested for presence of RF using both nephelometry and the Waaler test. Diagnostic sensitivity and predictive values of the tests were calculated and compared. The accuracy of tests was compared using receiver-operating characteristics (ROC) methodology.

Results Good agreement was found between the tests (kappa = $0.7)$. At cut-off $19 \mathrm{IU} / \mathrm{mL}$ nephelometry showed highest sensitivity $(82.4 \%)$ and specificity $(95.9 \%)$ for rheumatoid arthritis (RA). In comparison, the Waaler test had a sensitivity of $60.3 \%$ and specificity of $95.9 \%$ at cut-off titer 128 . The tests showed nearly equal performance characteristics when predicting primary Sjögren`s syndrome (SS).

Conclusion Although both tests exhibit good performance characteristics, nephelometry has a higher accuracy when predicting RA. The common practice of using both tests for detection of $\mathrm{RF}$ is not recommended. 


\section{SAT0190 HFE GENOTYPE IN PATIENTS WITH RHEUMATIC DISEASES}

MM Etemad, UH Hanusch-Enserer, KC Cauza, AD Dunky, EC Cauza. Department of Rheumatology/Medicine 5, Wilhelminenspital, Vienna, Austria

\subsection{6/annrheumdis-2001.688}

Background Hereditary haemochromatosis is a very common autosomal recessive disorder of iron metabolism. Among Northern Europeans the carrier frequency is estimated 1 in 10 , while up to 1 in 200 are affected by the disease. Arthropathy is one early clinical manifestation of this disease (the spectrum ranged from arthralgia to classic polyarthrits), but the articular features are often misdiagnosed. We tested the usefulness of measuring the HLA-linked haemochromatosis gene (HFE) in rheumatology clinic population.

Objectives

Methods Over a period of 12 month 203 consecutive patients, mean age 62.0 years (33 male/170 female) attending our rheumatologic clinic were screened for HFE mutations (C282Y and H63D). Mutations were evaluated by separation on PAGE of digest (by SnapI and Bcl-I, for C282Y and H63D, respectively) of PCR-amplificates of DNA obtained from PBMC's.

Results The C282Y and H63D allele frequencies were 6.9 and 18.2 in patients with rheumatic diseases. Five patients were homozygote for $\operatorname{H63D}(2.5 \%), 1$ for $\mathrm{C} 282 \mathrm{Y}(0.5 \%)$. Three patients were compound heterozygotes (1.4\%). Diagnosis of patients are summarised in Table 1. The observed C282Y allele frequency in rheumatic patients with undifferentiated arthritis exceeded that of healthy subjects or patients with chronic hepatitis $\mathrm{C}$ in Austria. ${ }^{1}$

\begin{tabular}{llllll}
\multicolumn{6}{l}{ Abstract SAT0190 Table 1} \\
\hline & C282Y/WT & H63D/WT & H63D/H63D & C282Y/C282Y & WT/WT \\
\hline Osteoarthritis & 14 & 21 & 4 & 0 & 82 \\
Undifferentiated & 0 & 0 & 0 & 1 & 5 \\
Rheumatoid & 1 & 12 & 1 & 0 & 47 \\
Psoriatic & 1 & 4 & 0 & 0 & 6 \\
Collagenosis & 0 & 0 & 0 & 0 & 3 \\
Temporal & 0 & 0 & 0 & 0 & 1 \\
Total & 16 & 37 & 5 & 1 & 144 \\
\hline Distribution of HFE Gene Mutation in 203 rheumatologic patients.
\end{tabular}

Conclusion Determination of HFE genotype is clinically useful in the group of patients with undifferentiated peripheral arthropathy and may lead to identification of otherwise unsuspected C282Y homozygotes.

\section{REFERENCE}

1 Kazemi, et al. Gastroenterology 1999;116(1):12-34

\section{SAT0191 QUANTITATIVE ULTRASOUND OF THE CALCANEUS IN PORTUGUESE CHILDREN AND ADOLESCENTS}

MM Costa, P Nero, E Branco, J Branco. Rheumatology, Hospital Egas Moniz, Lisbon, Portugal

10.1136/annrheumdis-2001.689

Background
Objectives The aim of this study was to determine value range of the parameters SOS, BUA and stiffness for Portuguese children and adolescents in age, sex and race groups.

Methods The study included 473 healthy children coming from two Lisbon schools. The population was $92,2 \%$ caucasian. There were $261(55,2 \%)$ girls and $212(44,8 \%)$ boys. Mean age was $10,7+2,4$ year, range 6-17 yr. The Sahara Clinical Sonometer of Hologic was used to performed a quantitative ultrasound (QUS) measurement of the non-dominant calcaneus. Patient examination was performed by two rheumatologists.

Results The mean of BUA, SOS and stiffness were: $70.07+19.82$ $\mathrm{db} / \mathrm{MHz}, 1563.64+26.65 \mathrm{~m} / \mathrm{s}$ and $98.96+17.7$.

There were no statistical differences between sex or race in each groups.

We observed an increased BUA, SOS and stiffness from 6 to 9 $\mathrm{yr}$ in caucasian boys and then stabilised. At this time the means were respectively $81.06 \mathrm{db} / \mathrm{MHz}, 1582 \mathrm{~m} / \mathrm{s}$ and 110.86 . In caucasian girls the increase of values occurred two years later and until 14 yr. The Spearman's rho correlation coefficient shown, in caucasian girls, a influence of age, height and weight on QUS parameters. In boys, this factors affect only SOS and stiffness. There were no correlation with this factors in black.

\begin{tabular}{llllll}
\multicolumn{6}{l}{ Abstract SAT0191 Table 1} \\
\hline & $\begin{array}{l}\text { Caucasian Girls } \\
(\mathbf{n}=240)\end{array}$ & $\begin{array}{l}\text { Caucasian Boys } \\
(\mathbf{n}=196)\end{array}$ & $\begin{array}{l}\text { Black Girls } \\
(\mathbf{n}=21)\end{array}$ & $\begin{array}{l}\text { Black Boys } \\
(\mathbf{n}=16)\end{array}$ & $\begin{array}{l}\text { Total } \mathbf{n}= \\
473\end{array}$ \\
\hline BUA & $69.14 \pm 18.49$ & $70.12 \pm 20.44$ & $76.99 \pm$ & $74.21 \pm$ & $70.07 \pm$ \\
& & & 26.07 & 21.85 & 19.82 \\
SOS & $1561.71 \pm 24.16$ & $1563.65 \pm 27.83$ & $1569.23 \pm$ & $1584.93 \pm$ & $1563.64 \pm$ \\
& & & 39.42 & 17.77 & 26.65 \\
Stiffness & $97.65 \pm 15.55$ & $99.20 \pm 19.26$ & $103.95 \pm$ & $109.25 \pm$ & $98.97 \pm$ \\
& & & 25.23 & 14.99 & 17.77 \\
BMD & 0.541 & $0.551 \pm 0.122$ & $0.581 \pm$ & 0.614 & $0.549 \pm$ \\
& & & 0.159 & & 0.112 \\
\hline
\end{tabular}

Conclusion Measuring bone mass of children by QUS is good technique. However reference data ranges must be developed for each population.

\section{SAT0192 RELATIONSHIP BETWEEN CLINICALLY DETECTED JOINT SWELLING AND EFFUSION DIAGNOSED BY ULTRASONOGRPAHY IN TALOCRURAL JOINTS IN PATIENTS WITH RHEUMATOID ARTHRITIS}

${ }^{1}$ RK Luukkainen, ${ }^{2} \mathrm{H}$ Huhtala, ${ }^{3} \mathrm{JM}$ KoskiHuhtala. 'Department of Rheumatology, Satalinna Hospital, Harjavalta; ${ }^{2}$ School of Public Health, University of Tampere, Tampere; ${ }^{3}$ Depatment of Medicine, Central Hospital of Mikkeli, Mikkeli, Finland

10.1136/annrheumdis-2001.690

Background In clinical investigation it is often difficult to know if there is effusion in talocrural (TC) joint or not.

Objectives To compare the relationship between clinically detected swelling and effusion diagnosed by ultrasonography (US) in TC joints in patients with rheumatoid arthritis (RA).

Methods Thirty-one consecutive patients with RA entered the study. Twenty healthy persons formed a control group. In clinical assessment the TC joint was evaluated on the scale: normal or swelling. The US of the same joints was carried out. Altogether 62 TC joints of the RA patients and 40 of those of the controls were studied. All the clinical assessments were performed by one 